\title{
Process modification involving strong-acid step in urea- formaldehyde resin preparation
}

\author{
Dicky Dermawan*, Lucky William Kusnadi, Jemmy Lesmana \\ Department of Chemical Engineering, Institut Teknologi Nasional, Jl. PHH Mustafa 23 Bandung 40124, Indonesia
}

* Corresponding author: dicky@itenas.ac.id

\section{Article history}

Received 6 March 2019

Revised 18 August 2019

Accepted 26 September 2019

Published Online 15 April 2020

\section{Graphical Abstract}

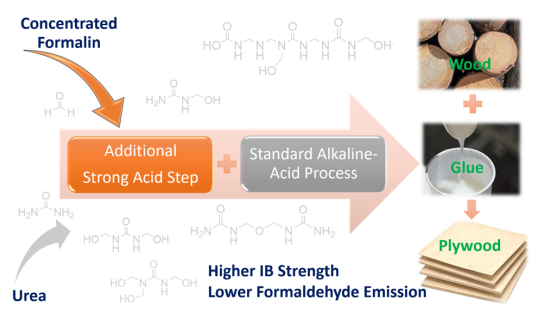

\begin{abstract}
Urea-formaldehyde (UF) resin adhesive for wood-based panel industries are commonly manufactured using conventional alkaline-acid process. This paper reports a process modification of a conventional UF resin preparation by incorporating a strong-acid step, involving simultaneous methylolation and condensation reactions at very low $\mathrm{pH}$ at the beginning of the processing step. The experiment showed that this additional step should be carried out at short duration and at high enough temperature in order to avoid gelation or separation problems. In order to control temperature rise caused by the exothermic nature of the reactions, the modified process requires a higher initial formaldehyde-to-urea (F/U) molar ratio compared to the original. For the same reason, the first urea should be fed incrementally to ensure high F/U ratio at any time during the strong acid step. Using regular formalin concentration as raw material at the same F/U molar ratio, the modified resin showed lower free formaldehyde content thus have lower reactivity in comparison to those of the original. However, when the same procedure was applied using higher formaldehyde concentration at higher solid content, the produced resin showed comparable free formaldehyde content and shorter gelation time. Application test for making plywood showed that the modified process gave a very significant improvement in both the internal bonding strength and formaldehyde emission.
\end{abstract}

Keywords: UF resin, plywood, alkaline-acid process, strong acid step

\section{INTRODUCTION}

As a natural and renewable material, wood has several advantages over other building materials. Wood's thermal, acoustic, mechanical, and aesthetic properties are very suitable for comfortable housing. Nevertheless, the ever-increasing price of log and lumber leads to the development of wood composites. Wood composites enable more consistent product properties (density, strength, durability), thus easily standardized. Interestingly, wood composites can be engineered to have special properties such as fire resistance, better bio-resistance, or have their surfaces improved for decorative purposes. Moreover, this engineered wood can be made by utilizing low-grade wood, wood residue, and even recycled material (Toemen et al., 2010).

Wood-based panels are made of wood elements (planks, veneer, chips, or fibers) which are glued together, frequently using synthetic adhesive. Urea-formaldehyde (UF) resin, despite its shortcomings such as poor water and weather resistance, is the most important and most widely used wood adhesive, with annual consumption of around 11 million tons of solid resin (Pizzi, 2016) because of its advantages such as low price, relatively low curing temperature, high heat resistance, and light color products (Dunky, 1998).

Formaldehyde is infamous for its harmful properties such as toxic by inhalation, ingestion, and skin absorption, as well as causing nasal and eye irritation at higher concentrations. Growing concern on health and environmental issues demands researchers to find safer alternative materials. The terms "eco-friendly" (Wu et al., 2018) or "greener" (Liu et al., 2018) UF resin were used to describe natural additive-containing UF resin. Greener, bio-sourced binders, namely furanic resins (Xi et al., 2018), unsaturated oil adhesives, proteins, polysaccharides (starch, chitosan, hemicelluloses), tannin, and lignin (Norstorm et al., 2018;
Gadhave et al., 2019) have been successfully developed to replace the usage of formaldehyde. Fully bio-based hybrid composites have been made using wood, fungal mycelium, and cellulose nanofibrils (Sun et al., 2019). Formaldehyde-free adhesives using glutaraldehyde, glyoxal, and furfural as formaldehyde substitute also have been used with some success (Akinyemi et al., 2019). However, the highly favorable costperformance characteristic and the high world consumption are the main reason why UF resin as a wood adhesive is not easily substituted by other materials.

Physical blending with various formaldehyde scavengers such as sodium metabisulphite (Costa et al., 2013), ammonium pentaborate (Gao et al., 2015), propylamine (Ghani et al., 2017), urea, and ammonium bicarbonate (Valyova et al., 2017) were also reported to reduce formaldehyde emission. Slow release, microcapsule-type scavenger were prepared by Duan et al. (2015). However, the use of scavengers is usually incorporated with lower mechanical properties because the scavengers cannot contribute to bonding strength. In addition, the reuse of cured UF resin residue to help in reducing the environmental impact of UF resin has been performed, but unfortunately this was followed by a decreased bonding strength (Zhong et al., 2017).

The key parameter in decreasing formaldehyde emission is lowering the formaldehyde/urea $(\mathrm{F} / \mathrm{U})$ molar ratio in the synthesis of UF resins, but this is also followed by a decrease in bonding strength (Nuryawan et al., 2017; Que et al., 2007). Lowering F/U molar ratio causing the cleavage of methylol groups in resin polymers thus decreasing degree of branching, resulted in more linear molecules, leading to partially cured resin with incomplete cross-linking polymer network. Moreover, the remaining unreacted urea cannot contribute to bonding strength. This leads to lower mechanical properties (Wang et 
al., 2018). At the microscopic level, lowering F/U molar ratio increase the average resin penetration into wood tissue, decreasing bond-line thickness (Nuryawan et al., 2014).

Structural characteristics of UF resin are strongly affected by conditions during preparation such as reaction time, temperature, $\mathrm{pH}$, and preparation procedure. Variation in operating conditions results in the variation of viscosity, as well as molecular weight, structure, and distribution. This relates to resin properties such as stability, dispersibility, and reactivity (Wu et al., 2016).

For UF resin polymer with monomethylolurea as shown in Fig. 1(a) (formed at low $\mathrm{F} / \mathrm{U}$ ) repeating unit, dominant in the more hydrophobic $-\mathrm{NH}_{2}$ moiety), an increase in degree of polymerization, $\mathrm{n}$, results in lower resin solubility, decreased stability, and lower reactivity. On the contrary, for UF resin polymer with dimethylolurea repeating unit [Fig. 1(b)], increasing $\mathrm{n}$ results in more favorable resin properties: higher resin solubility, higher stability, and higher reactivity (Giovanni et al, 1974).

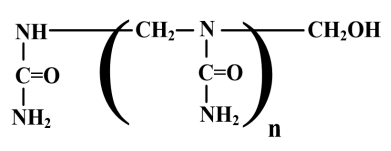

(a)

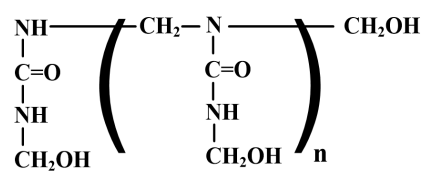

(b)
Fig. 1 UF resin polymers with (a) monomethylolurea (b) dimethylolurea repeating unit.

In general, UF resin preparation involves 2 reaction steps, i.e. methylolation (addition of formaldehyde molecule to urea), followed by condensation (polymer formation from urea and methylol-ureas). Methylolation is catalyzed by both acid and base, while condensation is exclusively acid-catalyzed (Conner, 1996). Methylolation in alkaline conditions is easier to control because at this condition, condensation process occurs very slowly (Fig. 2). For this reason, most industrial processes for UF resin preparation adopt alkaline conditions for methylolation, followed by $\mathrm{pH}$ adjustment to acid condition to facilitate condensation reaction. This method is well-known as the alkaline-acid process. The effect of different acids $\left(\mathrm{HCOOH}, \mathrm{HCl}, \mathrm{H}_{3} \mathrm{PO}_{4}, \mathrm{H}_{2} \mathrm{SO}_{4}\right)$ and latent acids $\left(\mathrm{NH}_{4} \mathrm{Cl},\left(\mathrm{NH}_{4}\right)_{2} \mathrm{SO}_{4}\right)$ used for $\mathrm{pH}$ adjustment in an alkaline-acid process have been studied by Dorieh et al. $(2018,2019)$.

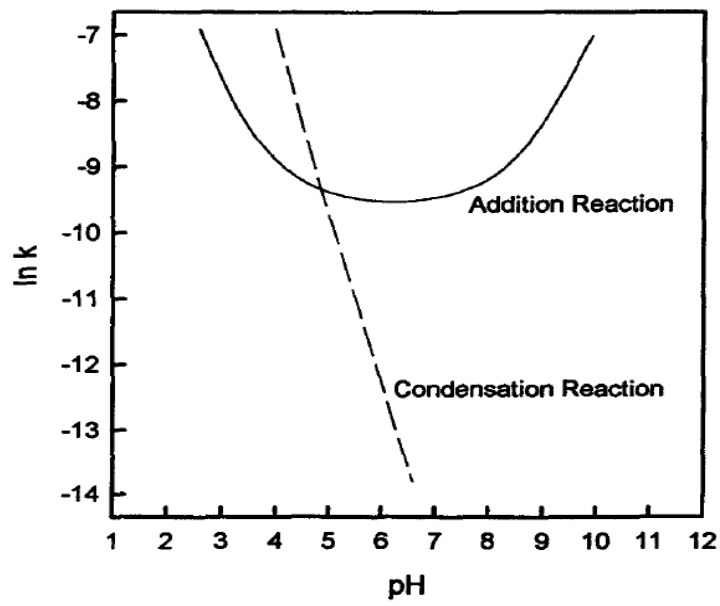

Fig. 2 Influence of $\mathrm{pH}$ on rate constant in UF resin synthesis (Conner, 1996).

Methylolation in strong acid condition facilitates a rapid formation of polymers right after methylol-ureas formation that may lead to the precipitation of insoluble high polymers. For this reason, Hatjiissaak and Papadopoulou (2007) stated that it is challenging to control the reaction condition in a strong acid process, especially at the industrial scale. It is important to keep a high $\mathrm{F} / \mathrm{U}$ molar ratio in the methylolation step to ensure the dominance of dimethylolurea formation. Taking into consideration the reversible nature of methylolation reactions, the ratio of slightly higher than 2.0 to 2.5 is usually used in alkaline-acid process.
In a strong acid process, even higher $\mathrm{F} / \mathrm{U}$ molar ratio is required to slow down the reactions in order to keep the reaction under control (Nocanda, 1998). Mixing should be enough to ensure no local high concentration of urea at any point in the reactor at any time to minimize the formation methylene-ureas and oligomer structures poor in methylol moiety such as depicted in Fig. 1(a). At acidic pH, the high molecular weight products increase as $\mathrm{F} / \mathrm{U}$ molar ratio decreases (Hse et al., 1994). Methylene-ureas with $\mathrm{n}=4-8$ lead to precipitation problems (Dunky, 1996). For these reasons, Williams (1983) proposed F/U molar ratio range of 2.5-3.5 with incremental addition of urea.

Despite the aforementioned difficulty in its preparation, methylolation in strong acid condition has several advantages over alkaline conditions. In alkaline condition, a high $\mathrm{F} / \mathrm{U}$ molar ratio promotes the formation of dimethylene-ether bonds which is more easily hydrolyzed, lead to lower bonding strength, and higher formaldehyde emission in the final wood product. On the contrary, strong acid condition does not result in any formation of dimethyleneether bond. Strong acid methylolation enables higher $\mathrm{F} / \mathrm{U}$ molar ratio in the final product, resulting in higher methylolated product with improved hydrolytic stability and enables the formation of tri- or even tetramethylolurea (Williams, 1983) which contribute to higher cohesive strength and improved resin wettability on wood substrate. The formation of uron derivatives under strongly acidic conditions responsible for the significant difference in resin properties from conventional alkaline-acid UF resins (Ferra et al., 2012).

It has been known that a mixture of higher and lower molecular weight species in resin provides a strong adhesion bond. Lower molecular weight resin penetrates better into wood tissues, contributing to the interfacial adhesion, while the higher molecular weight resin remains available in bond-line, contributing to cohesive adhesion. Thus, a UF resin of a higher polydispersity index is expected to give higher bonding strength. Ferra et al. (2012) showed that the strong acid process gave such a higher polydispersity index resin than the more industrially recognized alkaline-acid process. Thus, it is expected that resin produced using modified process involving strong acid step will show a high bonding strength. The resin produced by the strong acid process is also claimed to emit formaldehyde $40 \%-50 \%$ lower than the same resin produced by alkaline-acid process at the same final $\mathrm{F} / \mathrm{U}$ ratio (Williams, 1984). In order to yield a lower $\mathrm{F} / \mathrm{U}$ ratio in the final product, resin preparation is usually carried out in several steps, starting with a high $\mathrm{F} / \mathrm{U}$ ratio in the initial methylolation step, followed by additional urea feeding in the subsequent condensation step. It is also common to feed additional urea (called final urea) after cooling and neutralization to reduce formaldehyde content in the final product.In order to gain the described potential benefit of the strong acid process, this paper reports a process modification of UF resin preparation carried out by incorporating an additional strong acid step at the beginning of a standard conventional alkaline-acid process. Operational problems encountered in adopting a strong acid step are described and tackled. The effect of urea feeding frequency and duration in the strong acid step to resin properties (viscosity, solid content, gel time, and free formaldehyde content) are discussed and compared with the original resin. The beneficial effect of using more concentrated formalin as raw material to resin properties prepared by the modified process, as well as the effect of process modification to bonding strength and formaldehyde emission from plywood produced using this resin are also demonstrated.

\section{EXPERIMENTAL}

\section{Preparation of resin using standard alkaline-acid process}

The first urea was added at $\mathrm{F} / \mathrm{U}=2.30$ into a formalin solution of $37 \%$ strength. Several drops of $25 \mathrm{wt} \%$ caustic solution were added to adjust the $\mathrm{pH}$ to $7.8-8.0$. The mixture was stirred and heated to $80-90$ ${ }^{\circ} \mathrm{C}$. Afterward, the second urea was added to $\mathrm{F} / \mathrm{U}=2.15$. Reaction $\mathrm{pH}$ was then readjusted using the caustic solution to 7.5-8.0. After holding for $45 \mathrm{~min}$, the solution $\mathrm{pH}$ was adjusted to $4.2-4.5$ by the addition of $25 \mathrm{wt} \%$ formic acid solution to start the condensation step, which was proceeded for $50 \mathrm{~min}$ until the first end-point was accomplished, where a drop of resin water turns cloudy at $45^{\circ} \mathrm{C}$. In order to decrease the 
condensation rate, $\mathrm{pH}$ was then slightly increased to 5.2-5.5. The third urea was then added to reach $\mathrm{F} / \mathrm{U}=1.80$. This second condensation step was ended by adjusting $\mathrm{pH}$ to $6.8-7.2$ after $20-45 \mathrm{~min}$ when the second end-point was attained, indicated by the cloudy appearance of resin at $70{ }^{\circ} \mathrm{C}$. Borax $(0.1 \mathrm{wt} \%$ of total mass $)$ was then added. After cooling to $50{ }^{\circ} \mathrm{C}$, additional urea was added to reach final $\mathrm{F} / \mathrm{U}$ ratio of 1.60 . The upper part of Fig. 3 depicts process conditions of this standard resin.

\section{Modified process involving strong acid step}

The lower part of Fig. 3 depicts reaction conditions of the modified process. A formalin solution was first added drop-wise with $25 \mathrm{wt} \%$ $\mathrm{H}_{2} \mathrm{SO}_{4}$ solution in order to adjust its $\mathrm{pH}$ to 1 . To ensure a high $\mathrm{F} / \mathrm{U}$ molar ratio at any time during the methylolation step, urea was added incrementally to the formalin solution. Incremental additions of urea also prevent fast temperature increase due to exothermic nature of the reactions. Thus, first urea was added for 10 or 15 times every 1 or 2 min, each at the same weight such that at the end of this period, F/U reached 3.25. The temperature increase caused by exothermic reaction was permitted but was maintained not to exceed $90^{\circ} \mathrm{C}$. Cooling may be necessary to avoid excessive temperature, but precaution is advised as extreme temperature drop may cause gelation or separation problems. $25 \mathrm{wt} \%$ caustic solution was added drop-wise to neutralize the solution, effectively ending the strong acid step. Second urea was also added to reach $\mathrm{F} / \mathrm{U}=2.15$. The caustic solution was again added to adjust $\mathrm{pH}$ to 7.5-8.0. After holding for $20 \mathrm{~min}, \mathrm{pH}$ was adjusted to $4.2-4.5$ to start the condensation step. The subsequent steps were carried out using the same steps and conditions as the standard process. The experiment with modified process was carried out using 2 different formalin concentrations, i.e. $37 \mathrm{wt} \%$ and $50 \mathrm{wt} \%$.
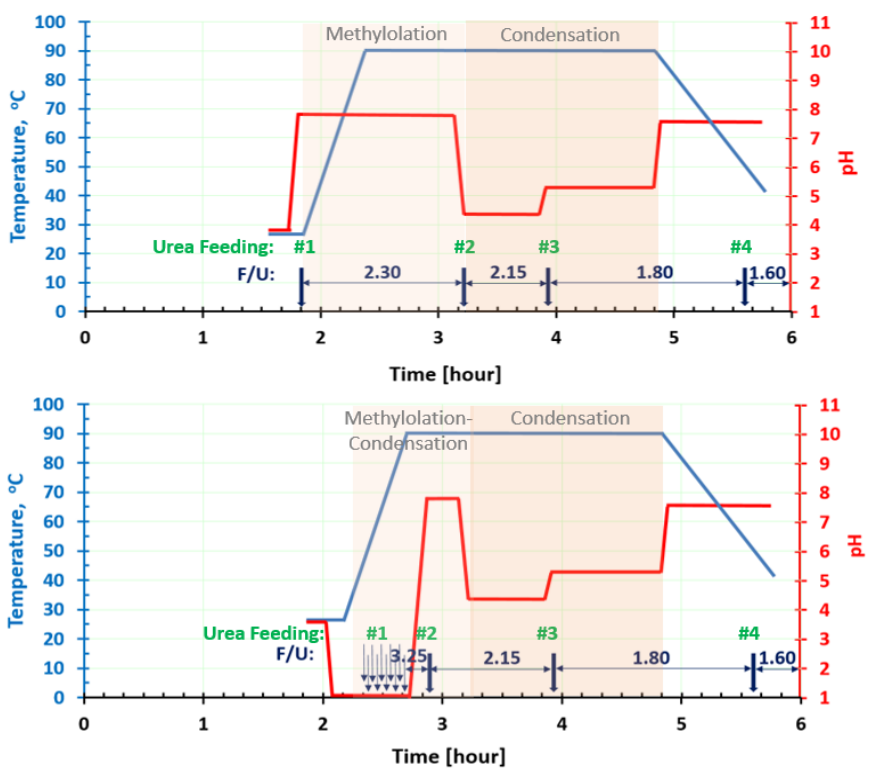

Fig. 3 Process conditions during resin preparation: standard process (upper), modified process (lower).

\section{Resin characterization}

The solid content was measured gravimetrically, calculated as the mass ratio of the sample after and before heated at $105^{\circ} \mathrm{C}$ for $3 \mathrm{~h}$.

Viscosity was measured using Brookfield viscometer at $25^{\circ} \mathrm{C}$.

Free formaldehyde content was measured by titration based on chemical reaction:

$$
6 \mathrm{CH}_{2} \mathrm{O}+4 \mathrm{NH}_{4} \mathrm{Cl} \rightarrow\left(\mathrm{CH}_{2}\right)_{6} \mathrm{~N}_{4}+4 \mathrm{HCl}+6 \mathrm{H}_{2} \mathrm{O} \text {. }
$$

Thus, a neutralized resin sample was added with excess $\mathrm{NH}_{4} \mathrm{Cl}$. After 30 minutes of holding time for reaction completion, excess $\mathrm{NaOH}$ was added. The resulting solution was then back-titrated using a standard $0.5080 \mathrm{M} \mathrm{HCl}$ solution. The same procedure was applied to a blank solution. Free formaldehyde content was calculated as:

$$
(B-S) \cdot 0.5080 \cdot 0.045 / \text { sample weight }
$$

where $\mathrm{B}$ and $\mathrm{S}$ are titration volume of sample and blank solution, respectively, in $\mathrm{mL}$.

Reactivity of resin is commonly indicated by gel time, preferrably shorter gel time because it enables shorter hot press duration in plywood production and higher speed line in continuous particleboard and MDF production. In other words, resin with shorter gel time enables higher productivity in wood products manufacturing. The gel time test was carried out at $100^{\circ} \mathrm{C}$ using aqueous $25 \mathrm{wt} \%$ solution of $\mathrm{NH}_{4} \mathrm{Cl}$ at 1 gram solid $\mathrm{NH}_{4} \mathrm{Cl}$ per 100 gram of solid resin. Gel time is measured as the time required for a mixture of $5 \mathrm{~g}$ resin and hardener at $100{ }^{\circ} \mathrm{C}$ to solidify or forming a gel.

\section{Resin application for making plywood}

Glue mix was prepared by mixing resin with $0.1-0.2 \mathrm{wt} \% \mathrm{NH}_{4} \mathrm{Cl}$ hardener and $12-16 \mathrm{wt} \%$ filler, resulting in glue mix of $18-20$ Poise viscosity. Plywood was made of 5 layers of Sengon wood plies with a dimension of $1 \mathrm{ft} \times 1 \mathrm{ft}$, with 3 core layers each of $3.1 \mathrm{~mm}$ thickness and a pair of $0.45 \mathrm{~mm}$ face/back plies. The moisture content of the wood was $12-14 \mathrm{wt} \%$ and $8-10 \mathrm{wt} \%$ for the core and face/back layer, respectively. Glue mix spread between cores was $2 \times 14=28 \mathrm{~g} / \mathrm{sqft}$. Both core surfaces were coated by glue mix and then pressed at a pressure of $9 \mathrm{~kg}_{f} / \mathrm{cm}^{2}$ for $30 \mathrm{~min}$ at room temperature. After 1 hour standing time, both outer core surfaces were bonded with face/back layers using glue spread of $2 \times 11=22 \mathrm{~g} / \mathrm{sqft}$. The plywood was then pressed for another $30 \mathrm{~min}$ at a pressure of $8 \mathrm{~kg}_{f} / \mathrm{cm}^{2}$. After another 1 hour standing time, the plywood was hot-pressed at $8 \mathrm{~kg}_{\mathrm{f}} / \mathrm{cm}^{2}$ for 255 seconds at a temperature of $95-100{ }^{\circ} \mathrm{C}$.

\section{Bonding strength test}

Plywood was cut to obtain 12 specimens of a dimension of $7.5 \mathrm{~cm}$ $\times 2.5 \mathrm{~cm}$. All specimens were immersed in water of $60^{\circ} \mathrm{C}$ temperature for 3 hours, then rinsed and allowed to cool and dry at room temperature. An increasing load was applied to each specimen until a maximum load was achieved, i.e. when the specimen was broken. The maximum stress, recorded as tensile stress, was corrected with the correction factor corresponding to the thickness ratio of core and face/back. Plywood is judged pass the test if corrected tensile stress of $90 \%$ (or higher) specimens reached over $0.7 \mathrm{MPa}$. Fig. 4 depicts a typical stress-strain curve of a bonding strength test.

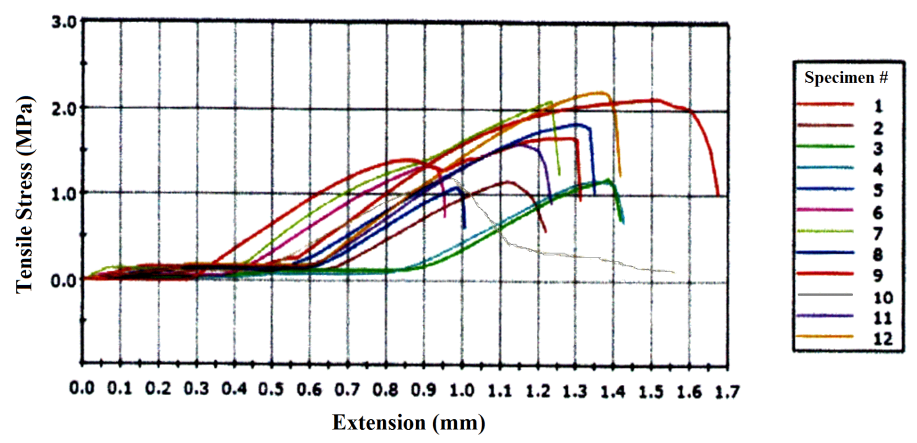

Fig. 4 Stress-strain curve of plywood bonded with UF resin prepared using the modified process (first urea feeding 10 times every $1 \mathrm{~min}$ ).

\section{Formaldehyde emission test}

The test was carried out according to JIS A 1460: 2001, i.e. desiccator method. Five plywood specimens, each of a dimension of 15 $\mathrm{cm} \times 5 \mathrm{~cm} \times 1 \mathrm{~cm}$, clamped using a metal clamp and placed in a glass desiccator (diameter $240 \mathrm{~mm}$, volume 9-11 L). The desiccator was conditioned in a room temperature of $(20 \pm 0.5){ }^{\circ} \mathrm{C}$ for 24 hours. Formaldehyde emitted from specimens was absorbed by $150 \mathrm{~mL}$ of distilled water contained in a petri dish $(120 \mathrm{~mm}$ in diameter, $60 \mathrm{~mm}$ height) which was placed below the specimens, at the bottom of the desiccator. Formaldehyde content in the sample solution was then analyzed using the spectrophotometric method at $412 \mathrm{~nm}$. The principle for determination of formaldehyde absorbed in distilled water is based on the Hantzsch reaction in which the formaldehyde reacts with ammonium ions and acetylacetone (Carvalho et al., 2012). 


\section{RESULTS AND DISCUSSION}

\section{Resin preparation}

In the first attempt, process modification was carried out using formaldehyde feed concentration of $37 \%$ (the same as those of the original process) at the initial $\mathrm{F} / \mathrm{U}$ molar ratio of 3.0 , with the initial temperature of $30{ }^{\circ} \mathrm{C}$. However, the process was failed at the first (methylolation-condensation) stage during the first urea addition due to a separation problem. The reaction mass turned into a turbid solution, indicating the early formation of insoluble high molecular weight polymer. A second attempt was then carried out by increasing the initial temperature to $40{ }^{\circ} \mathrm{C}$ but also failed due to resin gelation at prolonged reaction time during the second (condensation) stage. This indicates that a sufficiently high temperature in the first step is needed to increase resin solubility, thus avoiding gelling or separation problems.

In a strong acid environment, both methylolation and condensation proceed very fast. It is known that at $\mathrm{F} / \mathrm{U}$ higher than 4 is stable for prolonged periods of time (De Rooij, 1964) thus higher F/U ratio in this strong acid step is advantageous to slow down the reactions involved. Thus, the third attempt used an $\mathrm{F} / \mathrm{U}$ molar ratio of 3.25 and started with the initial temperature of $55^{\circ} \mathrm{C}$. This attempt was successful. In this condition, no separation nor gelation problem was encountered.

\section{Resin properties}

Table 1 summarizes resin properties prepared using the modified process. Varying frequency and duration of the first urea feeding in strong acid step seems not to give any important effect on resin properties, except for resin viscosity. Resin viscosity increase from 80 $\mathrm{cP}$ to $85 \mathrm{cP}$ and from $88 \mathrm{cP}$ to $100 \mathrm{cP}$ when the frequency of the first urea feeding increased from 10 to 15 times at feeding duration of $1 \mathrm{~min}$ and $2 \mathrm{~min}$, respectively, were merely caused by different reaction time in strong acid methylolation-condensation step. Thus, the resin of the total first urea feeding of $10,15,20$, and 30 min results in resin viscosity of $80,85,88$, and $100 \mathrm{cP}$, respectively. This was because, at the strong acid step, condensation reaction was also taken place at a high rate (Fig. 2) resulting in increasing viscosity. However, the same trend was not shown by other properties, due to the complex nature of the reactions involved, as well as limited accuracy in maintaining reaction conditions and properties measurements. For example, the difference in reaction temperature when final urea was added affects free formaldehyde content of the resin. Too high temperature causing higher portion of free formaldehyde reaction with the final urea, resulting resin in lower free formaldehyde content and longer gel time. Free formaldehyde of UF resin also decreases slowly due to chemical reactions during storage time.

Table 1 Effect of the first urea feeding on resin properties at $37 \mathrm{wt} \%$ formalin solution.

\begin{tabular}{ccccc}
\hline $\begin{array}{c}\text { First Urea } \\
\text { Feeding }\end{array}$ & $\begin{array}{c}\text { Solid } \\
\text { Content } \\
\text { [\%] }\end{array}$ & $\begin{array}{c}\text { Viscosity } \\
\text { [cP] }\end{array}$ & $\begin{array}{c}\text { Free } \\
\text { Formalin } \\
\text { Content } \\
{[\%]}\end{array}$ & $\begin{array}{c}\text { Gel Time } \\
\text { [sec] }\end{array}$ \\
\hline $10 \times$ @ 1 min & 47 & 80 & 0.20 & 282 \\
$10 \times$ @ 2 min & 48 & 88 & 0.27 & 264 \\
15 x @ 1 min & 47 & 85 & 0.30 & 258 \\
15 x @ 2 min & 46 & 100 & 0.24 & 271 \\
\hline Standard resin & $48-50$ & $95-180$ & $0.9-1.0$ & $35-50$ \\
\hline
\end{tabular}

Compared to the original resin prepared using formaldehyde feed concentration of $37 \%$ which gave $48-50 \%$ solid content, the modified strong acid process gave slightly lower value, i.e. 46-48\%. Solid content relates to polycondensation reaction conversion: the higher the conversion, the more the water molecules liberated, resulted in lower solid content of the remaining reaction mass. Thus, at the same formalin feed concentration, the modified process gave higher conversion thus higher molecular weight polymer, but at the same water solubility. In relation to molecular structure, this finding, as pointed by Edoga (2006), indicates that strong acid condition gave more dimethylolurea and higher methylolurea fraction, resulting in resin dominated by structure (b) in Fig. 1, which is actually more favorable for its application as wood adhesive. However, as shown in Table 1, the modified resins prepared using $37 \%$ formalin solution have gel time of 258-282 sec, much worse than the standard UF resin of 35-50 sec.

The free formaldehyde content is the explanation for the longer gel time: resins prepared with the modified process have much lower formaldehyde content of only $0.2-0.3 \mathrm{wt} \%$, while standard alkalineacid resin has free formaldehyde content of $0.9-1.0 \mathrm{wt} \%$. The tendency that resin production involving a strong acid step gave lower free formaldehyde content than that of the conventional alkaline-acid process was in agreement with the experiment of Edoga (2006). Lower free formaldehyde content causing incomplete conversion of hardener, thus lowering the quantity of acid formed, resulting in higher $\mathrm{pH}$ thus slowing down gel formation and resin curing.

\section{The effect of formalin feed concentration}

On one hand, lower free formaldehyde content shows a good indication to produce lower emission wood-based products, but on the other hand, too low free formaldehyde content hampers the use of UF resin due to unacceptably prolonged gel time. The use of more concentrated formalin as feed to the modified process is expected to increase the free formaldehyde content of the final resin, thus increasing its reactivity.

Table 2 shows the modified resins properties prepared using a formaldehyde concentration of $50 \mathrm{wt} \%$ at the same $\mathrm{F} / \mathrm{U}$ molar ratio and the same endpoint. These resins have relatively higher viscosity because they contain much higher solid content (59-61\%). The resins have free formaldehyde content of $0.85-0.95 \mathrm{wt} \%$, comparable to those of the standard resin, but with a little shorter gel time of $28-34 \mathrm{sec}$. Note that when the first urea was fed for 15 times every 2 minutes gelation problem encounter, possibly because the strong acid condition was applied for too long so that in this reaction step the extent of condensation reaction was too high. The tendency that more concentrated formalin feed results in higher solid content, higher free formaldehyde content and shorter gel time is also observed in the conventional alkaline-acid process ( $\mathrm{Wu}, 2016)$.

Table 2 Properties of strong acid process resin prepared using $50 \mathrm{wt} \%$ formalin solution.

\begin{tabular}{ccccc}
\hline $\begin{array}{c}\text { First Urea } \\
\text { Feeding }\end{array}$ & $\begin{array}{c}\text { Solid } \\
\text { Content } \\
{[\%]}\end{array}$ & $\begin{array}{c}\text { Viscosity } \\
\text { [cP] }\end{array}$ & $\begin{array}{c}\text { Free } \\
\text { Formalin } \\
\text { Content } \\
{[\%]}\end{array}$ & $\begin{array}{c}\text { Gel Time } \\
\text { [sec] }\end{array}$ \\
\hline $10 \times$ @ 1 min & 60 & 423 & 0.85 & 34 \\
$10 x @ 2$ min & 61 & 436 & 0.90 & 30 \\
$15 x @ 1$ min & 59 & 406 & 0.95 & 28 \\
$15 x @ 2$ min & gel & & & \\
\hline
\end{tabular}

\section{Application test}

Since the gel time of resin made with $37 \mathrm{wt} \%$ formalin was considered too long for practical application, only resin prepared using $50 \%$ formalin was used to bond veneer in making plywood for application test.

After resin and hardener were mixed, the hardener reacted with free formaldehyde contained in the resin. The reaction is exactly the same as the reaction took place during the above-described free formaldehyde and gel time analysis. This reaction slowly produced $\mathrm{HCl}$, gradually creating more and more acidic conditions that catalyzed a cross-linking reaction, converting the resin to higher molecular weight polymer with higher viscosity. Thus, $\mathrm{pH}$ of the glue mix slowly decreasing, resulted in accelerated reaction rate. Consequently, in the beginning, the viscosity increased slowly but this increase was accelerated by the additional $\mathrm{HCl}$ produced. Pot life is time required at $35{ }^{\circ} \mathrm{C}$ to increase glue mix viscosity to reach 100 Poise so that the glue mix converted to gel or was too viscous to spread properly at the surface of wood veneer. It is preferred to have a glue mix with high pot life. In the manufacture of plywood, time span from glue mix preparation and its use may extend to 240 minutes.

Fig. 5 shows that all glue mixed have good pot life, preferring short duration of the strong acid step. Resin prepared with more frequent urea feeding (15 times) showed shorter pot life, indicating higher reactivity. This is in agreement with the shorter gel time data shown in Table 2. 


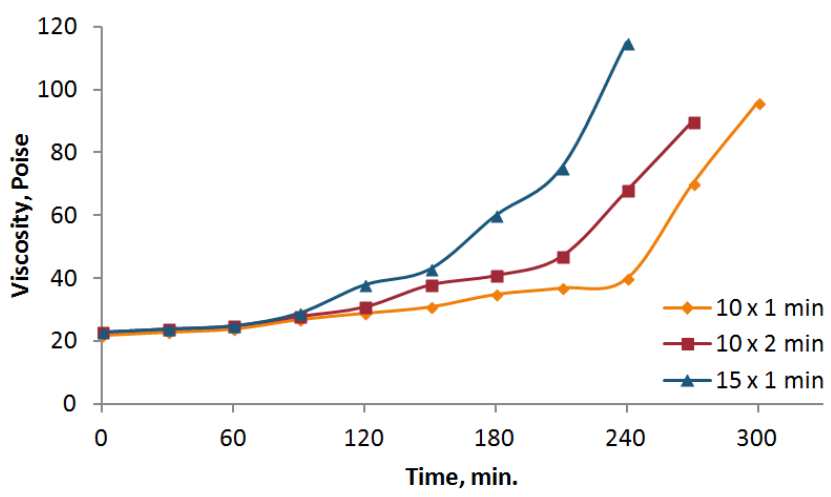

Fig. 5 Effect of first urea feeding on glue mix pot life.

Comparison of the internal bonding strength of plywood produced using the modified process and the original process in Fig. 6 clearly showed that all resin prepared using modified process gave better bonding strength: almost twice higher than the original process prepared at the same final $\mathrm{F} / \mathrm{U}$ molar ratio. This finding opens the possibility of applying lower glue dosing in plywood preparation, leading to reduced production cost.

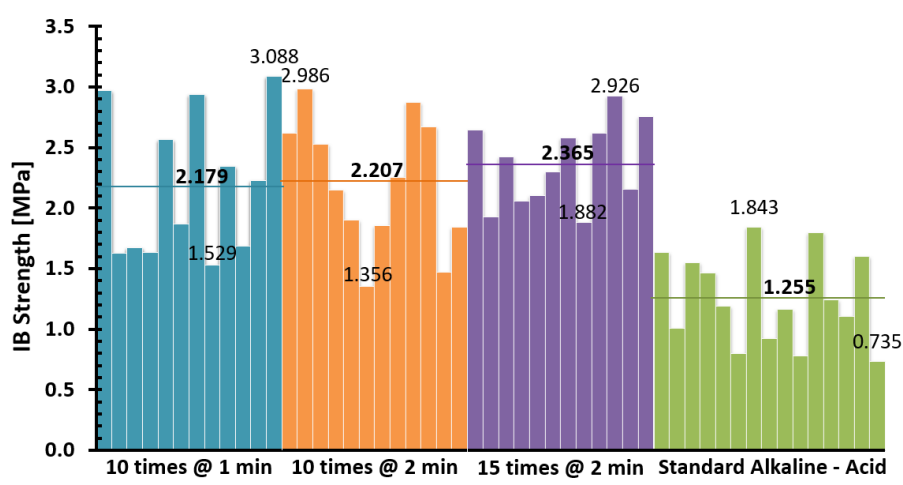

Fig. 6 Comparison of internal bonding strength of plywood bonded with UF resin prepared with original and modified process showing minimum, maximum, and average values.

Although free formaldehyde content of resins made using modified process is comparable to that of the standard alkaline-acid resin, emission test (Table 3 ) shows that the modified resins gave a significant improvement: the modified process gave formaldehyde emission of only $56-57 \%$ to that of the original, leading to better environment compliance.

Table 3 Effect of first urea feeding on formaldehyde emission.

\begin{tabular}{cc}
\hline First Urea Feeding & Formaldehyde Emission, $\mathbf{~ g} / \mathbf{L}$ \\
\hline $10 \mathrm{x} @ 1 \mathrm{~min}$ & 15.34 \\
$10 \mathrm{x} @ 2 \mathrm{~min}$ & 15.10 \\
$15 \mathrm{x} @ 1 \mathrm{~min}$ & 15.21 \\
\hline Standard Resin & 26.69 \\
\hline
\end{tabular}

Formaldehyde emission does not solely come from the remaining free formaldehyde content in resin. According to Zhang et al. (2018), formaldehyde emissions are mainly from three sources: (1) formaldehyde compound in wood material, (2) residual free formaldehyde of the resin, and (3) formaldehyde released by the structural degradation of the wood-based panel.

Reversibility of urea-formaldehyde reaction and acid-catalyzed hydrolysis are the main sources of emitted formaldehyde, especially dimethylene-ether bonds moiety which is formed during alkaline methylolation.

- Decomposition of dimethylene-ether bond during resin curing at hot press condition:

$\mathrm{RR}$ 'N-CH $2 \mathrm{O}_{2}-\mathrm{CH}_{2} \mathrm{NRR}^{\prime} \rightarrow$ RR'N-CH $\mathrm{RR}_{2}{ }^{\prime}+\mathrm{CH}_{2} \mathrm{O}$

- Hydrolysis of dimethylene-ether bond:

\section{RR'N-CH $\mathrm{H}_{2} \mathrm{O}-\mathrm{CH}_{2} \mathrm{NRR}^{\prime}+\mathrm{H}_{2} \mathrm{O} \rightarrow 2 \mathrm{RR}^{\prime} \mathrm{NCH}_{2} \mathrm{OH}+\mathrm{CH}_{2} \mathrm{O}$}

- Demethylolation:

$$
\mathrm{RR}^{\prime} \mathrm{N}-\mathrm{CH}_{2} \mathrm{O}-\mathrm{H} \rightarrow \mathrm{RR}^{\prime} \mathrm{NH}+\mathrm{CH}_{2} \mathrm{O}
$$

This encouraging result clearly shows that the modified process offers a myriad of advantages for producing lower emission UF resin but also with higher bonding strength.

\section{CONCLUSION}

In this study, a conventional alkaline-acid process for UF resin preparation is modified by incorporating an additional strong acid step at the beginning of the process. The experiment showed that this additional step should be carried out at short duration and at sufficiently high temperature in order to avoid resin gelation or separation problem. Using standard formalin concentration as raw material at the same $\mathrm{F} / \mathrm{U}$ ratio, UF resin prepared by modified process showed lower free formaldehyde content thus show lower reactivity in comparison to those of conventional process. Using higher formaldehyde concentration, thus at higher solid content, resulted in resin with comparable free formaldehyde content and gel time. Application test for making plywood showed that the modified process offers the potential for producing not only lower emission resin but also with higher bonding strength.

It can be inferred that process modification involving a strong acid step offer several advantages over the conventional alkaline-acid process. At the same free formaldehyde content and the same F/U ratio, the application of modified resin gave lower formaldehyde emission at the final wood products. Thus, lower formaldehyde emission can be achieved using the modified process without lowering the $\mathrm{F} / \mathrm{U}$ molar ratio which is normally followed by a decrease in bonding strength.

\section{ACKNOWLEDGMENT}

All laboratory works, resin preparation, analysis, and application tests were carried out using material and research facilities of the Production and Development Unit of PT Dover Chemical Indonesia.

\section{REFERENCES}

Akinyemi, B.A., Olamide, O., Oluwasogo, D. 2019. Formaldehyde-free particleboards from wood chip wastes using glutaraldehyde modified cassava starch as binder, Case Studies in Construction Materials 11, DOI: 10.1016/j.cscm.2019.e00236.

Carvalho, L.H., Magalhaes, F.D., Ferra, J. 2012. Formaldehyde emissions from wood-based panels - testing methods and industrial perspectives in Formaldehyde: Chemistry, Applications, and Role in Polymerization, Cheng, C.B. \& Lin, F.H. (eds), Nova Science Publishers, Inc., New York.

Conner, A.H. 1996. Urea-formaldehyde adhesive resins, Polymeric Materials Encyclopedia 11, 8496-8501, CRC Press Inc, Boca Raton.

Costa, N.A., Pereira, J., Ferra, J. Cruz, P., Martins, J., Magalhaes, F.D., Mendes, A. \& Carvalho, L.H. 2013. Sodium metabisulphite as a scavenger of air pollutants for wood-based building materials, International Wood Products Journal, 4 (4), 242-247, DOI: 10.1179/2042645313Y.0000000037.

De Rooij, A. H. 1963. Process for absorbing formaldehyde from a formaldehyde-containing gas, US Patent No. 3,151,960.

Dorieh, A., Mahmoodi, M.O., Mamaghani, M., Pizzi, A. \& Zeydi, M. M. 2018. Effect of different acids during the synthesis of urea-formaldehyde adhesives and the mechanical properties of medium-density fiberboards bonded with them, Journal of Applied Polymer Science, DOI: 10.1002/app.47256.

Dorieh, A., Mahmoodi, M.O., Mamaghani, M., Pizzi, A., Zeydi, M. M. \& Moslemi, A. 2019. New insight into the use of latent catalysts for the synthesis of urea-formaldehyde adhesives and the mechanical properties of medium density fiberboards bonded with them, European Polymer Journal 112, 195 205, DOI: 10.1016/j.eurpolymj.2019.01.002.

Duan, H., Qiu, T., Guo, L., Ye, J. \& Li, X. 2015. The microcapsule-type formaldehyde scavenger: the preparation and the application in ureaformaldehyde adhesives. Journal of Hazardous Material 293, 46-53, DOI: 10.1016/j.jhazmat.2015.03.037.

Dunky, M. 1996. Urea-formaldehyde adhesive resins, Polymeric Materials Encyclopedia 11, 8502-8510, CRC Press Inc, Boca Raton.

Dunky, M. 1998. Urea-formaldehyde (UF) adhesive resins of wood, International Journal of Adhesion and Adhesives 18, 95-107, DOI: 10.1016/S0143-7496(97)00054-7. 
Edoga, M. O. 2006. Comparative study of synthesis procedures for ureaformaldehyde resins (part I), Leonardo Electronic Journal of Practices and Technologies 9, 63-80.

Ferra, J.M.M., Henriques, A., Mendes, A.M., Costa, M.R.N., Carvalho, L.H. \& Magalhaes, F.D. 2012. Comparison of urea-formaldehyde synthesis by alkaline-acid and strongly acid processes, Journal of Applied Polymer Science, DOI: 10.1002/app.34642.

Gadhave, R.V., Srivastava, S., Mahanwar, P.A. \& Gadekar, P.T. 2019. Lignin Renewable Raw Material for Adhesive, Open Journal of Polymer Chemistry, 9, 27-38, DOI: 10.4236/ojpchem.2019.92003.

Gao, W., Du, G. \& Kamdem, D.P. 2015. Influence of ammonium pentaborate (APB) on the performance of urea-formaldehyde (UF) adhesives for plywood, The Journal of Adhesion, 91 (3), 186-196, DOI: 10.1080/ 00218464.2013 .874294$.

Ghani, A., Bawon, P., Ashaari, Z., Wahab, M.W., Hua, L.S. 2017. Addition of propylamine as formaldehyde scavenger for urea formaldehyde-bonded particleboard, Wood Research, 62 (2), 329-334.

Giovanni, S., Mazzoleni, G., Nistri, U. \& Vargiu S, 1974. Process for the preparation of resins from urea, formaldehyde, methanol and formic acid using three stages, US Patent No. 3,830,783.

Hse, C.Y., Xia, Z.Y. \& Tomita, B. 1994. Effects of reaction $\mathrm{pH}$ on properties and performance of urea-formaldehyde resins, Holzforschung 48, 527-532.

Hatjiissaak, A. \& Papadopoulou, E. 2007. Aminoplast resin of high performance for lignocellulosic materials, WO Patent Appl. No. 2007138364 A1.

Liu, M., Wang, Y., Wu, Y., He, Z., Wan, H. 2018. "Greener" adhesives composed of urea-formaldehyde resin and cottonseed meal for wood-based composites, Journal of Cleaner Production, 187, 361-371.

Nocanda, X.W. 1998. A synthetic and spectrometric study of the initial phases in urea-formaldehyde resin formation," MS thesis, Rhodes University.

Norström, E., Demircan, D., Khabbaz, F., Fogelström, L. \& Malmström, E. 2018. Green Binders for Wood Adhesives, in Applied Adhesive Bonding in Science and Technology, Ozer H. (ed), DOI: 10.5772/intechopen. 68926.

Nuryawan, A. Byung-Dae Park \& Singh, A.P. 2014. Penetration of ureaformaldehyde resins with different formaldehyde/urea mole ratios into softwood tissues, Wood Sci. Technol 48, 889-902, DOI: 10.1007/s00226-0140649-9.

Nuryawan, A., Risnasari, I., Sucipto, T., Iswanto, A.H. \& Dewi, R.R. 2017. Urea-formaldehyde resins: production, application, and testing, IOP Conf. Series: Materials Science and Engineering, DOI: 10.1088/1757899X/223/1/012053.
Pizzi, A. 2016. Wood products and green chemistry. Annals of Forest Science 73, 185-203.

Que, Z., Furuno, T., Katoha, S. \& Nishino, Y. 2007. Effects of ureaformaldehyde resin mole ratio on the properties of particleboard, Building and Environment 42, DOI: 10.1016/j.buildenv. 2005.11.028.

Sun, W., Tajvidi, M., Hunt, C.G., McIntyre, G. \& Gardner, D.J. 2019. Fully BioBased Hybrid Composites Made of Wood, Fungal Mycelium and Cellulose Nanofibrils, Scientific Reports 9(1):3766, DOI: 10.1038/s41598-019-404428 .

Thoemen, H., Irle, M. \& Sernek, M. 2010. Wood-Based Panels - An Introduction for Specialists, Brunel University Press, London, ISBN: 978-1902316-82-6.

Valyova, M., Ivanova, Y. \& Koynov, D. 2017. Investigation of free formaldehyde quantity in the production of plywood with modified ureaformaldehyde resin, Wood, Design \& Technology, 6 (1), 72-77.

Wang, H., Cao, M., Li, T., Yang, L., Duan, Z., Zhou, Z. \& Du, G. 2018. Characterization of the low molar ratio urea-formaldehyde resin with ${ }^{13} \mathrm{C}$ NMR and ESI-MS: negative effects of the post-added urea on the ureaformaldehyde polymers, Polymers 10,602, DOI:10.3390/polym10060602.

Williams, J. H. 1983. Hydrolytically stable urea-formaldehyde resins and process for manufacturing them, US Patent No. 4,410,685.

Williams, J. H. 1984. Low emitting aqueous formulations of aminoplast resins and processes for manufacturing them, US Patent No. 4,482,699.

Wu, Z., Lei, H., Du, G., Cao, M., Xi, X. \& Liang, J. 2016. Urea-formaldehyde resin prepared with concentrated formaldehyde, Journal of Adhesion Science and Technology, DOI: 10.1080/01694243.2016.1193963.

Wu, Z., Xi, X., Yu, L. \& Su, L. 2018. An eco-friendly urea-formaldehyde resin: preparation, structure and properties, Wood research 63 (1), 45-56

Xi, X., Wu, Z., Pizzi, A., Gerardin, C., Lei, H. \& Du, G. 2018. Furfuryl alcoholaldehyde plywood adhesive resins, The Journal of Adhesion, DOI: 10.1080/00218464.2018.1519435.

Zhang, J., Song, F., Tao, J., Zhang, Z., \& Shi, 2018. Research progress on formaldehyde emission of wood-based panel, International Journal of Polymer Science, DOI: 10.1155/2018/9349721.

Zhong, R., Gu, J., Gao, Z., Tu, D. \& Hu, C. 2017. Impacts of urea-formaldehyde resin residue on recycling and reconstitution of wood-based panels, International Journal of Adhesion and Adhesives 78, DOI: 10.1016/j.ijadhadh.2017.06.019. 